\title{
Vulnerabilidade econômica: produto da erosão costeira em Ajuruteua - Bragança/PA
}

\author{
Economic vulnerability: resulting from coastal erosion in Ajuruteua - Bragança/PA \\ Vulnerabilidad económica: resultante de la erosión costera en Ajuruteua - Bragança/PA
}

Recebido: 23/11/2021 | Revisado: 02/12/2021 | Aceito: 06/12/2021 | Publicado: 08/12/2021

\author{
Hygson da Silva Rodrigues \\ ORCID: https://orcid.org/0000-0001-6892-6211 \\ Corpo de Bombeiros Militar do Pará, Brasil \\ E-mail: hygson_bmf@yahoo.com.br \\ Aline Maria Meiguins de Lima \\ ORCID: https://orcid.org/0000-0002-0594-0187 \\ Universidade Federal do Pará, Brasil \\ E-mail: ameiguins@ufpa.br \\ Paulo Afonso Fisher Kuhn \\ ORCID: https://orcid.org/0000-0001-7155-4340 \\ Universidade Federal do Pará, Brasil \\ E-mail: pkuhn@ufpa.br \\ Hernani José Brazão Rodrigues \\ ORCID: https://orcid.org/0000-0002-5509-6287 \\ Universidade Federal do Pará, Brasil \\ E-mail: hernani@ufpa.br \\ Edson José Paulino da Rocha \\ ORCID: https://orcid.org/0000-0002-2509-7027 \\ Universidade Federal do Pará, Brasil \\ E-mail: eprocha@ufpa.br
}

\begin{abstract}
Resumo
A praia de Ajuruteua (Bragança-Pará-Brasil) sofre transformações dinâmicas pelo processo de erosão marinha, gerando diversas consequências ambientais e na qualidade de vida da comunidade local. Este trabalho teve por objetivo estimar pelo Método de Valoração do Custo de Reposição (MVCR) às perdas econômicas geradas direta e indiretamente pela erosão hídrica, visando auxiliar o poder público para gestão da praia e de seu aproveitamento turístico. O método adotado empregou questionários e listagem de verificação, aplicados a uma amostra de 81 estabelecimentos, para identificação dos custos das perdas (prejuízos) e de recuperação/reconstrução (total ou parcial) do patrimônio afetado. Como resultado se obteve um custo/prejuízo geral na ordem $\mathrm{R} \$ 4.165 .000,00$ vinculado a perda parcial e/ou total de imóveis, aos investimentos em recuperação, reconstrução ou realocação. E um Custo geral de Reposição (CR) médio de $\mathrm{R} \$ 6.325 .889,40$; indicando que as perdas socioeconômicas podem ser admitidas como significativas, devendo ser repensadas no sentido do ordenamento e da gestão do espaço costeiro.
\end{abstract}

Palavras-chave: Erosão marinha; Uso e ocupação; Gestão; Valoração econômica.

\begin{abstract}
The Ajuruteua beach (Bragança-Pará-Brazil) undergoes dynamic changes by the process of marine erosion, generating several environmental and quality of life, from local community, consequences. This study aimed to estimate by the Replacement Cost Valuation Method (MVCR) the economic losses generated directly and indirectly by water erosion, in the assistance of the beach management process and its tourist use by the public authorities. The adopted method employed questionnaires and checklists, applied to a sample of 81 establishments, to identify the costs of losses and recovery/reconstruction (total or partial) of the affected assets. The result obtained a general cost/loss in the order of $\mathrm{R}$ $\$ 4,165,000.00$ linked to partial and/or total loss of properties, investments in restoration, reconstruction or relocation. And an average General Replacement Cost (CR) of $\mathrm{R} \$ 6,325,889.40$; indicating that socioeconomic losses can be admitted as significant and should be rethought in the sense of planning and coastal space management.
\end{abstract}

Keywords: Marine erosion; Use and occupation; Management; Economic valuation.

\section{Resumen}

La playa de Ajuruteua (Bragança-Pará-Brasil) sufre transformaciones dinámicas debido al proceso de erosión marina, generando varias consecuencias ambientales y sobre la calidad de vida de la comunidad local. El objetivo de este trabajo fue estimar por el Método de Valoración del Costo de Reposición (MVCR) las pérdidas económicas generadas directa e indirectamente por la erosión hídrica, con el objetivo de ayudar a las autoridades públicas en la gestión de la playa y su uso turístico. El método adoptado utilizó cuestionarios y listas de verificación, aplicados a una muestra de 81 establecimientos, para identificar los costos de pérdidas (pérdidas) y de recuperación/reconstrucción (total o parcial) de la propiedad afectada. El resultado obtuvo un costo/pérdida general del orden de $\mathrm{R} \$ 4.165 .000,00$ vinculado a la pérdida 
parcial y/o total de inmuebles, inversiones en recuperación, reconstrucción o relocalización. Y un Costo General de Reposición (CR) promedio de R \$ 6.325.889,40; indicando que las pérdidas socioeconómicas pueden admitirse como significativas, y deben repensarse en términos de planificación y gestión del espacio costero.

Palabras clave: Erosión marina; Uso y ocupación; Manejo; Valoración económica.

\section{Introdução}

A intervenção humana associada a erosão costeira tem sido feita, na maioria das vezes, de uma forma empírica muito localizada e focalizada em dar resposta a situações de emergência, sem uma abordagem apropriada a um sistema heterogêneo, amplo e dinâmico com a participação da população e/ou do poder público local. Contudo, a gestão destes espaços permanece, ainda, complexa e dispersa por vários agentes de atuação, que culmina em uma fragmentação e enfraquecimento de responsabilidades quando se trata de tomadas de decisão referentes ao ordenamento do território.

A contabilidade dos efeitos da erosão costeira tem sido importante para identificar e prevenir impactos socioeconômicos nas cidades litorâneas, entretanto, a escassez de dados de monitoramento é um obstáculo difícil de ser vencido (Ribeiro et al., 2013). Estudos mostraram que o nível médio dos oceanos já subiu em média 20 centímetros entre 1900 e 2012; em tal situação, segundo os cenários tratados no AR5 (Relatório de Avaliação) do IPCC (Painel Intergovernamental sobre Mudanças Climáticas), se a taxa de elevação dos oceanos exceder outros 60 centímetros, com a atuação das forçantes hidrodinâmicas, sobretudo os regimes de marés e clima de ondas, o resultado será uma forte erosão nas áreas costeiras de todo o planeta (Santos et al., 2015).

A erosão costeira pode ser caracterizada como um processo físico responsável pelo desgaste da linha de costa, com a remoção e redistribuição de sedimentos, sendo conduzida normalmente por forças naturais, tais como a ação das ondas e correntes de marés; os sedimentos normalmente são redistribuídos ao longo da costa, fornecendo material para dunas e praias, sua ação continuada pode resultar na perda de terras com valor econômico e/ou ecológico (Prasad \& Kumar, 2014; Bruno et al., 2019).

Logo, a discussão sobre a vulnerabilidade das áreas localizadas na zona costeira envolve tanto os componentes naturais quanto os antrópicos instalados, um exemplo disto está no reflexo das mudanças climáticas nestes ambientes, que podem trazer danos significativos como o aumento do nível das águas e a intensificação dos processos atmosféricos, resultando assim em perdas diversas vinculadas aos sistemas associados (Mullick et al., 2019; Zucatelli et al., 2019; Victral et al., 2020). Outro fator de destaque está no incremento da erosividade pluvial, cujas flutuações precisam ser quantificadas de forma a reduzir o risco ambiental destas áreas, que reflete a relação entre as forçantes climáticas e as características morfológicas do ambiente de costa sobre os aspectos socioeconômicos e culturais locais, estes últimos, em geral se traduzem em perdas relativas ao potencial turístico da região (Díaz-Cuevas et al., 2020; França et al., 2020; Anfuso et al., 2021).

Para se realizar a valoração econômica dos efeitos do processo de erosão é necessária uma compreensão prévia dos impactos causados pelo agente degradante; os definidos como "efeitos internos" estão ligados à perda da eficiência da sustentabilidade do solo associada ao processo erosivo gerando danos a estrutura das edificações ou causando o desmoronamento/desabamento das mesmas, onde os prejuízos são absorvidos pelos próprios proprietários, aumentando assim seus custos de reconstrução no curto e médio prazo; e os "efeitos externos" são absorvidos por outros indicadores econômicos, por exemplo, aqueles associados a perda de clientes, hospedes, redução da margem de lucro dentre outros (Tôsto et al., 2007; De Serio et al., 2016; Van Assche et al., 2019). Neste processo, destacam-se as abordagens baseadas na preferência das pessoas relativas a: disposição para pagar, de obter uma melhoria ambiental ou evitar uma deterioração ambiental e a disposição para aceitar compensação pelos danos sofridos (Markantonis et al., 2012). Tal decisão, na maioria das vezes, vincula-se a forma de interpretação do impacto ocorrido como: direto, que inclui perdas financeiras por danos aos ativos econômicos, como por exemplo, danos à construção; indireto, associado a interrupção dos processos de produção, a perda de produtos e fontes de 
receita; e o secundário, relativos à inibição do crescimento econômico e aumento das taxas de pobreza (Suryanto et al., 2017; Armenio et al., 2019).

A avaliação econômica dos efeitos da evolução de processos erosivos e consequente perdas de solo, incluindo o patrimônio econômico agregado ou ambiental, pode ser observada em trabalhos como de Igwe e Fukuoka (2010), Vaz e Bowman (2013), Mohamad et al. (2014) e Eric e Rémi (2015). Enríquez et al. (2017) analisam os efeitos da erosão associados aos impactos do aumento do nível do mar, que segundo estes agregam a ocorrência de eventos extremos, taxas de erosão, alterações morfológicas, inundações e vulnerabilidade das infraestruturas.

O litoral paraense está sujeito a um regime de macromarés semi-diurnas, com variação de altura máxima de 4,0 a 7,5 m, abrangendo uma área de aproximadamente $8.900 \mathrm{~km}^{2}$ (Souza Filho et al., 2003; Braga et al., 2007; Ranieri \& El-Robrini, 2015). A Praia de Ajuruteua, localizada no município de Bragança, nordeste do Pará, foi selecionada como área de estudo em função de representar uma das praias mais frequentadas do litoral paraense, assim como por estar situada em Bragança-PA, um dos municípios paraenses de potencial crescimento urbano, associado ao turístico comercial e a pesca, que demonstram ser rentáveis na região (Ribeiro, 2018).

Esta vem sofrendo constantemente com a erosão marinha, processo este influenciado pela combinação de fatores e fenômenos físicos, tais como: a temporada de chuvas (inverno), ventos fortes, temperatura da água e a maré alta, esta provocada pela combinação das fases de lua (cheia e nova), além de outros, inclusive os derivados de ações antrópicas (Gomes et al., 2009). Uma das principais atividades econômicas da Praia de Ajuruteua está ligada ao setor terciário da economia, representado pelo intenso fluxo turístico. Durante o mês de julho, quando ocorre a maior frequência de turistas, cerca de 45 mil pessoas passam pela Praia de Ajuruteua a cada fim de semana (Mendes et al., 2013).

Em grande parte das áreas litorâneas do Brasil, o turismo impõe grande influência sobre a realidade socioambiental, gerando impactos positivos (ex.: empregos, renda e melhoria de infraestruturas urbanas) e também negativos (ex.: crescimento desordenado, desigualdades sociais e degradação do meio ambiente); desta forma as localidades turísticas têm dificuldades em solucionar os problemas de saneamento básico e de degradação dos sistemas ambientais, em geral adotando soluções de curto prazo que prejudicam o potencial futuro para o desenvolvimento turístico (Costa, 2011).

Entender as perdas decorrentes da erosão costeira e discutir as ações de ordenamento do território necessárias para sua mitigação são elementos essenciais para melhoria das condições socioambientais e econômicas para sociedade local. Considerando o caso de Ajuruteua-Braganca/PA, este trabalho teve por objetivo realizar a valoração dos danos gerados pelo processo de erosão hídrica na área de orla marinha, identificando os elementos de vulnerabilidade social e econômica instalados.

\section{Metodologia}

A praia de Ajuruteua localizada na faixa costeira do município de Bragança, na região NE do Estado do Pará; tem cerca de 2,5 km de extensão e está a $36 \mathrm{~km}$ da cidade de Bragança (Figura 1), sendo delimitada entre uma área de cobertura de manguezais, as águas do Furo da Estiva e o mar (Pereira et al., 2006).

O clima da área é equatorial, quente e úmido, e está caracterizado por uma estação muito chuvosa entre os meses de dezembro e maio, e uma estação seca, nos demais meses do ano. A pluviosidade média anual é de 2.500 a $3.000 \mathrm{~mm} / \mathrm{ano}$; a umidade relativa do ar varia entre 80 e $91 \%$; a temperatura média do ar é de $25,7{ }^{\circ} \mathrm{C}$, podendo variar entre $20,4{ }^{\circ} \mathrm{C}$ e $32,8^{\circ} \mathrm{C}$; na região predomina o regime de macromarés semidiurnas (4- $6 \mathrm{~m}$ ); ocorrem ventos alísios de $\mathrm{NE}$, com velocidades médias de $7,9 \mathrm{~m} / \mathrm{s}$, principalmente, entre os meses de dezembro e maio, estes são geralmente precedidos de calmaria e, quase sempre, acompanhados de rajadas violentas e chuvas intensas; entre os meses de junho e novembro, predominam os ventos E e SE, com intensidades moderadas (Pereira et al., 2006; Barbosa et al., 2007). 

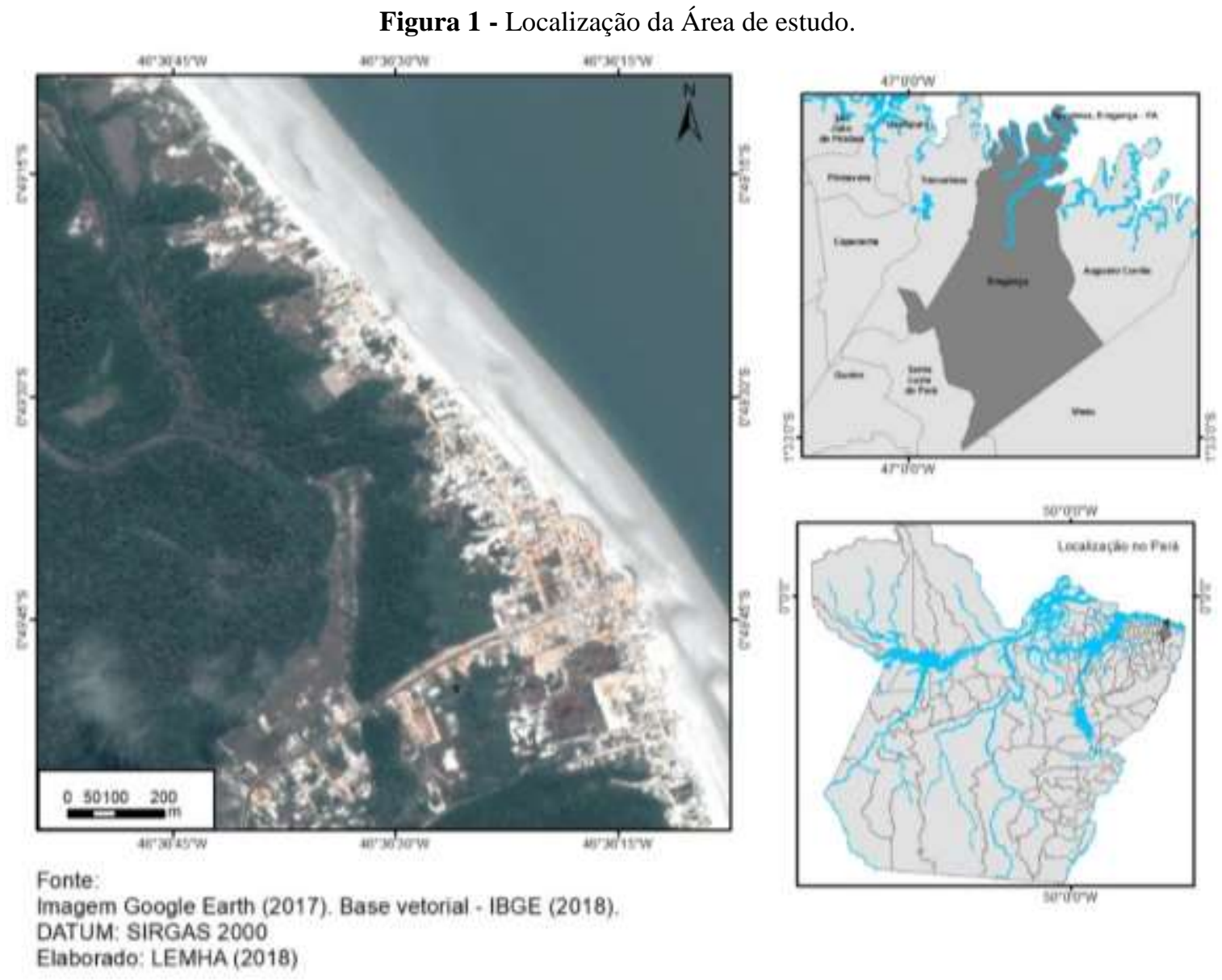

Fonte: Rodrigues (2018).

As marés locais são semidiurnas e assimétricas, as elevações máximas são entre 5,0 e 5,5 m ocorrem durante as marés de equinócio de março e setembro; os padrões de circulação são dominados pelas correntes de maré, que fluem para o noroeste durante a maré de refluxo e para o sudeste durante a maré de inundação (Oliveira et al., 2011).

De acordo com El-Robrini et al. (2006) o padrão de uma célula de circulação para a praia de Ajuruteua, parece obedecer ao sistema de correntes de retorno com ondas normais à costa e a morfologia dos perfis poderia ser considerada como a zona de shoaling (perda de energia), situada entre as duas calhas (Calliari et al., 2003); os perfis praiais apresentam uma zona de intermaré superior com uma largura média entre 35 e $45 \mathrm{~m}$, limitada, em alguns trechos, por um campo de dunas frontais de 1,5 a 3 m de altura, no período chuvoso, ocorre erosão das dunas frontais, formando-se escarpas praiais de 1,8 a 3 m, a morfologia dos perfis causa recuos de até $25 \mathrm{~m}$ na linha de costa; a zona de intermaré média, por sua vez apresenta uma largura variando de 98 a 130 m (Figura 2).

O evento de macromaré equinocial de sizígia constitui um fator preponderante na modificação da configuração morfológica da praia de Ajuruteua, refletindo consideráveis transformações morfodinâmicas de curto período que corresponderam a dados quantitativos (erosão/acresção) dos subambientes praiais (Barbosa et al., 2007; Braga et al., 2007; Monteiro et al., 2009). 
Figura 2 - Morfodinâmica da praia de Ajuruteua.
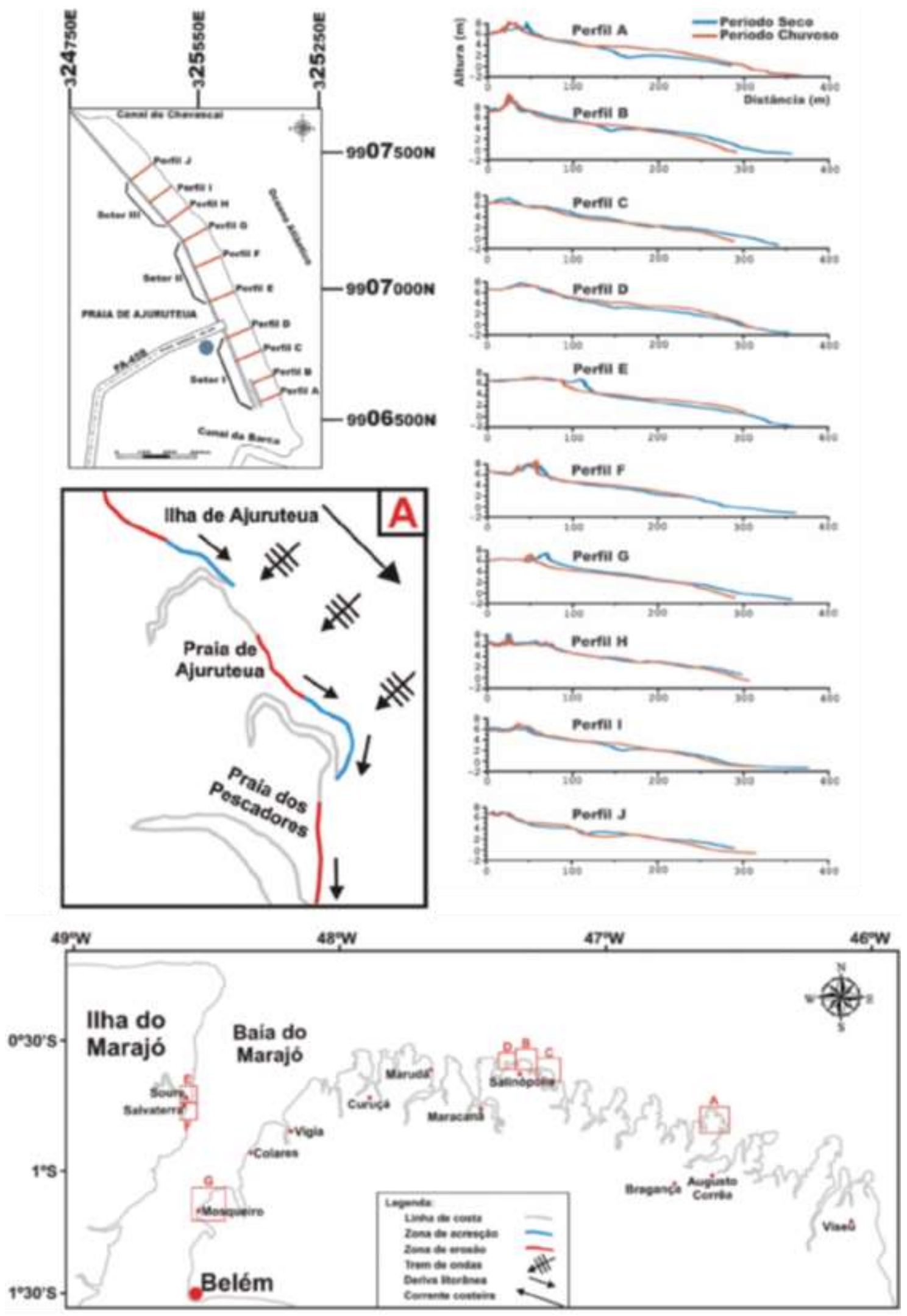

Fonte: Adaptado de El-Robrini et al. (2006). 


\subsection{Base de informações}

Os dados primários foram coletados através de questionários semi-estruturados aplicados a uma amostra aleatória de unidade habitacionais (bares, restaurantes, pousadas e residências), na praia e de moradores, comerciantes e proprietários das unidades habitacionais atingidas e das passiveis de serem atingidas pelo desastre. $\mathrm{O}$ objetivo foi avaliar os custos (preço de mercado) das perdas ocasionada pela erosão, na área afetada e de risco iminente.

A listagem de verificação (Checklist) sobre os danos e prejuízos causados pelo fenômeno, permitiu também avaliar os investimentos necessários para a recuperação do dano, sobre o patrimônio existente no local, e, coletar informações sobre a possibilidade de remanejamento para outro local mais seguro.

Na descrição das características físicas e econômicas dos empreendimentos foi adotada uma classificação de função das perdas: 5 (perda muito alta), 4 (perda alta), 3 (perda moderada), 2 (perda baixa) a 1 (perda muito baixa a nenhuma).

Para a valoração econômica dos danos gerados pelo processo de erosão marítima foi utilizado o "Método de Valoração do Custo de Reposição - MVCR" (Tôsto et al., 2007; Pereira et al., 2015). O MVCR analisa as perdas pelo investimento em recuperação dos danos e/ou perda total do bem sem recuperação do dano. Foram levantados os seguintes pontos: (a) Perdas pela recuperação dos danos causados pela erosão costeira; (b) Perdas pela reconstrução/realocação dos danos causados pela destruição total do bem; e (c) Perda total do bem, sem recuperação dos danos causados.

No MVCR os preços dos elementos e das ações necessárias aos trabalhos de restauração são orçados e o valor obtido é imputado ao agente causador; o custo de reposição representa o valor econômico mínimo causado pelo dano e, nesse caso, o valor venal do imóvel onde a degradação ocorreu não influenciará a valoração, o cálculo final do valor de um dano deve incluir o preço das perdas econômicas diretas e indiretas, desde a ocorrência do dano até a completa recuperação do ambiente (Corrêa \& Souza, 2013).

Adaptando-se o proposto por Corrêa e Souza (2013) e Vergara et al. (2014) para o problema analisado, foi adotada a equação 01. Onde: CR - Custo de Reposição, em reais; $\mathrm{N}$ - Número de domicílios/áreas comerciais afetadas; $\mathrm{CU}_{\mathrm{i}}$ - Custo unitário interno, em reais; $\mathrm{CU}_{\mathrm{e}}$ - Custo unitário externo, em reais:

$$
C R=\left(\begin{array}{lll}
N & x & C U_{i}
\end{array}\right)+\left(\begin{array}{lll}
N & x & C U_{e}
\end{array}\right) \quad \text { eq. } 01
$$

O Custo de Reposição foi obtido a partir de dados catalogados de imóveis localizados na área do "setor de risco muito alto", com base no trabalho elaborados pelo Serviço Geológico do Brasil (CPRM, 2015). Onde nesta área encontram-se edificações, na área de orla (perigo de desabamento), que já foram e/ou serão atingidas diretamente pela ação das ondas nos próximos eventos (equinócio sizígia). Para estas edificações foram estimados os Custos Unitários Internos (CU) e o Custo unitário externo $\left(\mathrm{CU}_{\mathrm{e}}\right)$.

\section{Resultados e Discussão}

\subsection{Histórico de ocupação}

A praia de Ajuruteua vem passando por um processo de mudanças que atinge além da estrutura morfológica da linha de costa (relacionadas a perda de sedimentos), as edificações (residências, bares, pousadas e restaurantes) que estão situadas na linha do recuo costeiro. Esta até a década de 1970 era ocupada por pequeno grupo de pescadores, a partir da implantação da rodovia que liga a cidade de Bragança até Ajuruteua esse cenário foi alterado (Pereira et al., 2006). Monteiro et al. (2009) constataram que a praia de Ajuruteua possuía 392 residentes permanentes, dos quais, 52,55\% eram do sexo masculino e 47,45\% do sexo feminino; onde a maior parte da população era solteira; sendo as faixas etárias dominantes de 11 e 20 anos (22,7\%) e entre 41 e 64 anos (21,23\%). O grau médio de escolaridade era muito baixo, com 87,75\% da população acima de 15 anos não tendo concluído a $4^{\mathrm{a}}$ série do Ensino Fundamental e 7\% eram analfabetos. 
O relato de um dos moradores mais antigos de Ajuruteua, descreve que na década de 60, nos meses de julho, as embarcações conduziam moradores de Bragança, veranistas e outros curiosos para a praia de Ajuruteua. E que alguns barcos viraram (naufragaram) no trajeto, e em um destes acontecimentos morreram umas seis pessoas. Por este motivo, foi elaborado o projeto de lei para a construção da estrada que liga Bragança a Ajuruteua, na década de 1970. A construção da estrada teve início em 1973 e foi concluída dez anos mais tarde, em 17/12/1983. Em 1993 foi asfaltada pela primeira vez.

Localmente, a partir das entrevistas realizadas, os piores eventos que acarretaram em prejuízos locais aconteceram nos anos de 1984, 1985 e 1986. Desde o início da ocupação até os dias atuais novas moradias vêm sendo construídas em Ajuruteua, sejam por filhos de pescadores (nativos), novos moradores ou por empresários que se estabelecem no intuito de explorar o comércio/lazer/turismo com a finalidade de gerar lucro, emprego e renda para a população que vive em Ajuruteua. Porém, este padrão de ocupação se mantém continuo e desordenado, sem controle ou fiscalização por parte do poder público local.

\subsection{Padrão de uso da terra}

A Figura 3 apresenta o zoneamento realizado em função das zonas de ocupação e das formas de cobertura da terra. Observa-se o padrão paralelo a linha de costa e sua tendência de resposta com o avanço das alterações morfológicas sofridas e a modificação da cobertura vegetal.

Figura 3 - Zoneamento do uso e cobertura da terra.
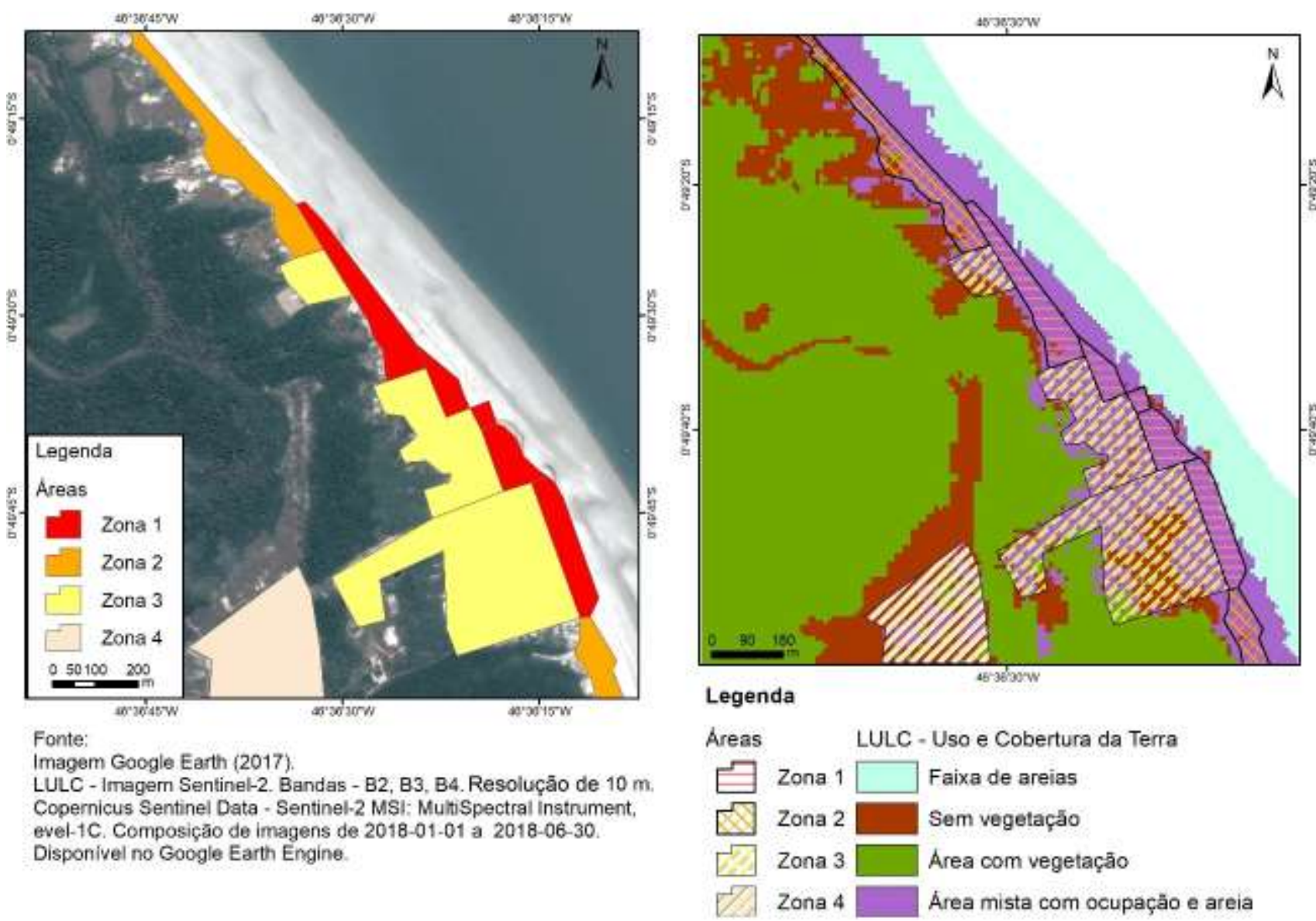

Fonte: Autores.

$\mathrm{Na}$ tentativa de prevenir ou retardar a ação erosiva, os moradores e/ou comerciantes fizeram inúmeras barreiras de contenção com diversos tipos de materiais diferentes; estes serviram apenas como medidas paliativas para conter 
momentaneamente o processo erosivo. As infraestruturas mais utilizadas para contenção ou proteção dos processos erosivos são: materiais como a pedra de rachão que foram colocadas de forma aleatória, visando apenas o melhor arranjo, em pontos isolados para proteger áreas e bens específicos; saco de areia, aterro, pedras, piçarra; além de tábuas de madeira; pneus de caminhão; concreto armado, etc. Apesar de utilizarem esses matérias para tentar conter a ação da maré, estes mostraram-se de baixa eficiência frente a força das ondas nos dias de maré de sizígia, período em que ocorre as maiores amplitudes de ondas (chegando até 5,5 m). Para tentar conter a erosão foram dispostos blocos de rochas em áreas pontuais, em frente a alguns estabelecimentos comerciais e residência. Esta contenção artificial tem surtido efeito localmente de forma paliativa/atenuante e de curto prazo e não de forma definitiva, visto que a ação da maré continua erodindo (removendo) o material que está a baixo da contenção de pedras (rochas).

Estudos realizados pela CPRM (2015) indicaram que a erosão costeira vem aumentando ao longo do tempo, onde imagens de satélite dos anos de 2007 e 2014 demonstraram que nesse período teve um recuo estimado de $25 \mathrm{~m}$, em média. Os fatores que interferem na intensidade do processo são principalmente: alteração das formas de cobertura vegetal e a construção de edificações (residências, bares, pousadas e restaurantes). Pereira et al. (2006) já destacavam que intensos processos erosivos, principalmente no setor NW, estavam destruindo muitos estabelecimentos (bares, casas e pousadas); e que cerca de 2,21 m/mês de linha de praia foram recuados neste setor, enquanto no setor SE a linha de praia crescia 1,46 m/mês.

Espirito-Santo e Szlafsztein (2016) afirmam que na Vila dos Pescadores (Bragança), $500 \mathrm{~m}$ da praia foram erodidos no período de 1996 a 2001 e 50 m de 1998 a 1999, sendo que nos últimos 30 anos houve redução de 60\% do número de casas; e que na praia de Ajuruteua existem evidências de fortes processos erosivos, com o recuo de $22 \mathrm{~m}$ da linha de costa no ano 2000, explicados pela proximidade da praia com as margens de canais de maré, pelo ângulo de incidência de ondas e pela amplitude de maré.

Estes processos devem ser discutidos frente aos elementos naturais de maior intervenção, como destacado por Ranieri e El-Robrini (2015) que descrevem que a região está sujeita a ondas formadas a partir dos ventos alísios, que cruzam a plataforma continental em direção a SW, gerando "trends" de ondas incidentes; as correntes de marés atuam com velocidade máxima de 2 $\mathrm{m} / \mathrm{s}$ durante a maré de sizígia, secundariamente, as correntes litorâneas resultantes da chegada das ondas à costa, são responsáveis pelo transporte de grandes quantidades de sedimentos da plataforma continental para o litoral.

Sendo assim, faz-se necessário avaliar o uso desta área e quantificar as perdas associadas às diferentes respostas morfodinâmicas, provavelmente ligadas aos diferentes ambientes de energia que a praia está submetida, principalmente nas áreas em que existem zonas mais exposta às variações dos ventos, correntes de marés e ondas e, portanto, as variações onde as morfológicas são mais evidentes (Gomes et al., 2009).

\subsection{Perdas Econômicas}

A base de dados do Sistema Nacional de Proteção e Defesa Civil (SINPDEC), através dos dados do Formulário de Informações do Desastre (FIDE), informa que houve 8 (oito) registros de ocorrências de desastres relacionados a erosão costeira/marinha na praia de Ajuruteua (Bragança-PA) no período de julho de 2014 a março de 2018 (Tabela 1).

Estes fenômenos ocasionaram perdas econômicas e ambientais estimadas na ordem de $\mathrm{R} \$ 30.327 .051,15$, deste quantitativo R \$ 2.377.759,56 são perdas pela danificação ou destruição de unidades habitacionais (Bares, restaurantes, pousadas e residências). Inclusos também neste total estão: R\$ 12.340.719,06 em obras de infraestrutura pública; $R$ \$ 336.593,32 nas instalações públicas de uso comunitário (praça e ruas); $\mathrm{R} \$ 13.742 .975,21$ os prejuízos econômicos públicos (abastecimento de água potável, canais de escoamento pluvial, sistemas de esgoto, sistema de limpeza urbana, recolhimento e destinação do lixo, geração e distribuição de energia elétrica); e R \$ 1.529.004,00 em prejuízos econômicos privados (comercio e serviços). 
Tabela 1 - Perdas vinculadas a desastres naturais em Ajuruteua (Bragança - PA).

\begin{tabular}{|c|c|c|c|c|c|c|}
\hline \multirow[b]{2}{*}{ Ano } & \multirow[b]{2}{*}{ Data } & \multicolumn{3}{|c|}{ PESSOAS } & \multirow[b]{2}{*}{$\begin{array}{l}\text { Inst. Pub. de uso } \\
\text { Comunitário }\end{array}$} & \multirow{2}{*}{$\begin{array}{c}\text { Obras de } \\
\text { Infraestrutura } \\
\text { Pública }\end{array}$} \\
\hline & & $\begin{array}{l}\text { Desabrigada/ } \\
\text { Desalojada }\end{array}$ & Outros afetados & Total & & \\
\hline 2014 & $12 / 07 / 2014$ & 0 & 0 & 0 & $200.000,00$ & 580,00 \\
\hline \multirow{2}{*}{2015} & $21 / 02 / 2015$ & 1 & 109 & 110 & 0,00 & $6.000,00$ \\
\hline & $30 / 10 / 2015$ & 0 & 0 & 0 & $100.000,00$ & $100.000,00$ \\
\hline \multirow{3}{*}{2016} & $21 / 01 / 2016$ & 0 & 110 & 110 & 0,00 & $16.591,20$ \\
\hline & $09 / 02 / 2016$ & 0 & 400 & 400 & $19.000,00$ & 0 \\
\hline & $18 / 03 / 2016$ & 0 & 5 & 5 & 0,00 & 0 \\
\hline 2017 & $11 / 02 / 2017$ & 15 & 585 & 600 & $17.593,32$ & $12.117 .538,86$ \\
\hline 2018 & $03 / 03 / 2018$ & 17 & 583 & 600 & 0,00 & $100.000,00$ \\
\hline \multicolumn{2}{|r|}{ Total } & 33 & 1.792 & 1.825 & $336.593,32$ & $12.340 .719,06$ \\
\hline
\end{tabular}

\begin{tabular}{c|c|c|c|c|c}
\hline \multirow{2}{*}{ Ano } & \multirow{2}{*}{ Data } & \multicolumn{2}{|c|}{ Unidades Habitacionais } & \multirow{2}{*}{$\begin{array}{c}\text { Prejuízos econômicos } \\
\text { públicos e privados }\end{array}$} & Prejuízos econômicos privados \\
\cline { 3 - 6 } & & $\begin{array}{c}|c| \\
\text { Danificadas/ } \\
\text { Destruídas }\end{array}$ & Total & & \\
\hline \multirow{2}{*}{2014} & $12 / 07 / 2014$ & 0 & 0,00 & 0,00 & 0,00 \\
\hline \multirow{2}{*}{2015} & $21 / 02 / 2015$ & 17 & $840.043,00$ & 0,00 & 0,00 \\
\cline { 3 - 6 } & $30 / 10 / 2015$ & 0 & 0,00 & $35.000,00$ & 0,00 \\
\hline \multirow{2}{*}{2016} & $21 / 01 / 2016$ & 8 & $181.000,00$ & $41.000,00$ & $328.000,00$ \\
\cline { 2 - 6 } & $09 / 02 / 2016$ & 2 & $11.000,00$ & 0,00 & $65.000,00$ \\
\cline { 2 - 6 } & $18 / 03 / 2016$ & 8 & $517.000,00$ & $13.456 .975,21$ & $976.004,00$ \\
\hline 2017 & $11 / 02 / 2017$ & 6 & $398.716,56$ & $210.000,00$ & $100.000,00$ \\
\hline 2018 & $03 / 03 / 2018$ & 9 & $430.000,00$ & $13.742 .975,21$ & $1.529 .004,00$ \\
\hline
\end{tabular}

Fonte: Dados do Formulário de Informações do Desastre - FIDE.

Em 21/02/2015, 17 unidades habitacionais foram afetadas pelo evento, provocando um prejuízo estimado em $\mathrm{R}$ \$ 840.043,00 com a danificação ou destruição dos imóveis, sendo 110 pessoas prejudicadas e dentre estas uma ficou desalojada. Em 21/01/2016 houve destruição integral e parcial de pousadas além de danos ambientais como a poluição e contaminação do solo e da água.

O evento de 18/03/2016 contabilizou R \$ 517.000,00 para 8 unidades habitacionais, dentre estas, ao menos 3 empreendimentos (bar, pousada e restaurante) tiveram perda total. O registrado em 03/03/2018, consta do período de 01 a 05 de março de 2018, e danificou/destruiu 9 unidades habitacionais causando um prejuízo de R 430.000,00 deixando 12 pessoas desabrigadas, 5 desalojadas e outras 583 foram afetadas diretamente por questão do turismo e comercio que ficaram prejudicados no período.

Com base nos dados estima-se que houve uma queda de $25 \%$ no movimento financeiro dos estabelecimentos localizados nas áreas afetadas pelos desastres, atingindo segundo os dados da Defesa Civil de Bragança e da Secretaria de Patrimônio da União (SPU) 23 edificações, com 129 casas sendo classificadas como de alto risco e 527 imóveis com potencial de serem afetados.

As consequências do processo de erosão costeira para a praia de Ajuruteua são graves por se tratar de uma praia bastante requisitada por turistas e veranistas (uma das principais fontes de renda) (Pereira, 2007), que visitam durante todo o ano e para lazer, o descanso e a prática de esportes terrestres e náuticos, onde o mar gera ondas propícias à prática do surf, e tem condições de ventos favoráveis para a pratica de kite surf (sediando campeonatos estaduais e regionais). E, principalmente para os 
moradores, comerciantes e donos de pousadas que sofrem com a destruição de seus bens e com os prejuízos diretos e indiretamente causados pela erosão.

\subsection{Valoração dos custos}

Para a avaliação dos custos foram selecionadas e catalogadas 22 edificações (bares, pousadas e restaurantes) com histórico de impactos vinculados a erosão costeira. Estas foram atingidas diretamente pela ação marinha e tiveram perdas econômicas, associadas as respostas morfodinâmicas, total (destruição total do imóvel) ou parcial (destruição parcial do imóvel); e necessitaram dispor de recursos econômicos para recuperação, reconstrução ou realocação de seus bens danificados.

O levantamento aponta que 15 das edificações pesquisadas ao serem atingidas pela ação das ondas sofreram perda total de seus imóveis, e seus proprietários tiveram de executar investimentos financeiros para reconstruir (no mesmo local), realocar (construir em outro local) seus imóveis ou tiveram de absorver seus prejuízos por não terem recursos financeiros para sua respectiva restruturação (Figuras 4 e 5). Sendo as médias para as edificações com Perda Total em torno de: "Valor Estimado da Perda" de R \$ 127.000,00; “Investimento em Reconstrução" de R \$ 104.000,00; “Investimento em Relocação" de R \$ 125.000,00; e "Sem reconstrução ou relocação" de $\mathrm{R} \$ 73.000,00$. E as com Perda Parcial em torno de: "Valor Estimado da Perda" de R \$ 33.000,00; "Perda Parcial sem Recuperação" de R \$ 10.000,00; e “Investimento em Recuperação" de R \$ 13.000,00.

Figura 4 - Edificações com perda total.

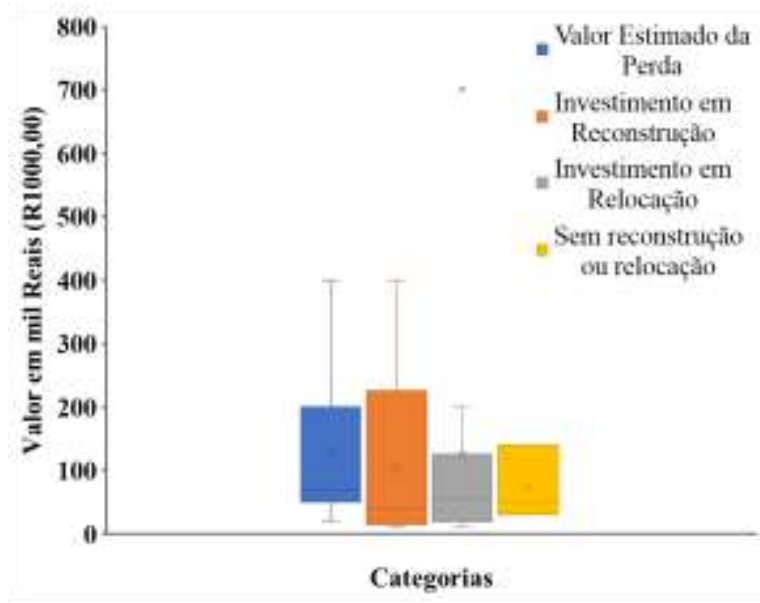

Fonte: Autores.
Figura 5 - Edificações com perda parcial.

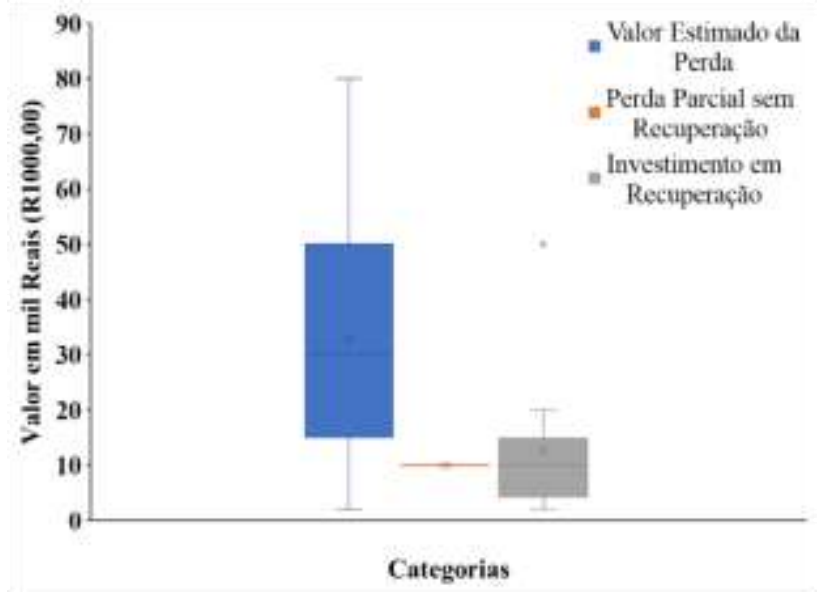

Fonte: Autores.

Observando um investimento de cerca de $40 \%$ na recuperação. Calculados a partir da soma de valores, estimados, dos respectivos prejuízos e/ou investimentos, identificou-se que, a perda total destas 15 edificações está na ordem de $\mathrm{R}$ \$ 1.905.000,00, sendo feitos investimentos para reconstrução na ordem de $\mathrm{R}$ \$ 520.000,00 e/ou investimentos de $\mathrm{R} \$ 1.251 .000,00$ na realocação (em outros terrenos) e 3 proprietários absorveram seus respectivos prejuízos, que somados dão $\mathrm{R} \$ 220.000,00$ por não terem condições de reinvestir, reconstruir ou realocar seus imóveis para uma tentativa de recuperação econômica. Por outro lado, neste mesmo período, 11 edificações tiveram perdas parciais em decorrência da dinâmica de maré em períodos de sizígia. Estas perdas parciais somadas totalizaram um montante de $\mathrm{R} \$ 362.000,00$. Os respectivos proprietários fizeram investimentos em recuperação de suas propriedades, na ordem total de $\mathrm{R} \$ 127.000,00$.

Dentre as 22 edificações pesquisadas, 4 delas tiveram seus estabelecimentos comerciais atingidos por fenômenos distintos, contraindo perdas, parcial em um evento e total em outro, estando assim com prejuízos majorados no período. Estimando as perdas total e parcial, tem-se $\mathrm{R} \$ 362.000,00$ em perdas parciais e $\mathrm{R} \$ 1.905 .000,00$ na perda total dos imóveis, chegando a um montante estimado de $\mathrm{R} \$ 2.267 .000,00$. Da mesma forma houve a contabilização dos investimentos financeiros 
por parte de 6 (seis) proprietários, e estes investimentos foram executados em momentos distintos e provocados por eventos diferentes. Assim, estes chegam a um montante de $\mathrm{R} \$ 1.898 .000,00$ no período, com uma demanda média de $\mathrm{R} \$ 127.000,00 \mathrm{em}$ recuperação, $\mathrm{R}$ \$520.000,00 em reconstrução e $\mathrm{R}$ \$ 1.251.000,00 em realocação dos imóveis (Figuras 6 e 7).

Figura 6 - Perdas parcial e total no período.

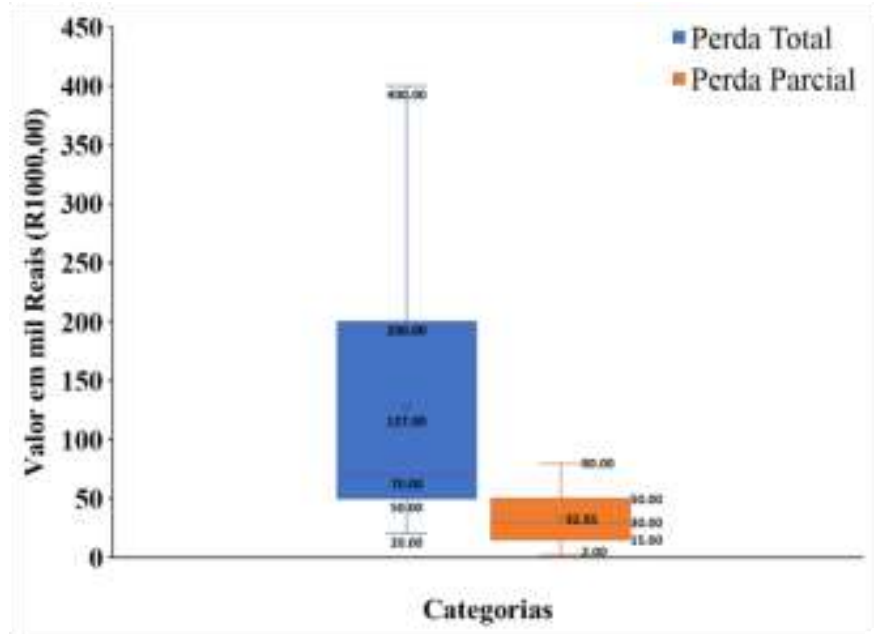

Fonte: Autores.

Figura 7 - Investimentos financeiros.

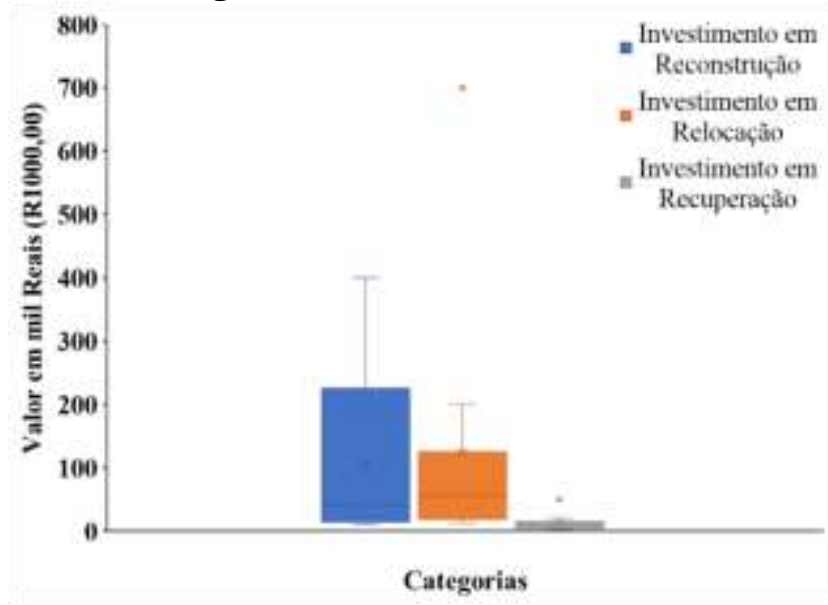

Fonte: Autores.

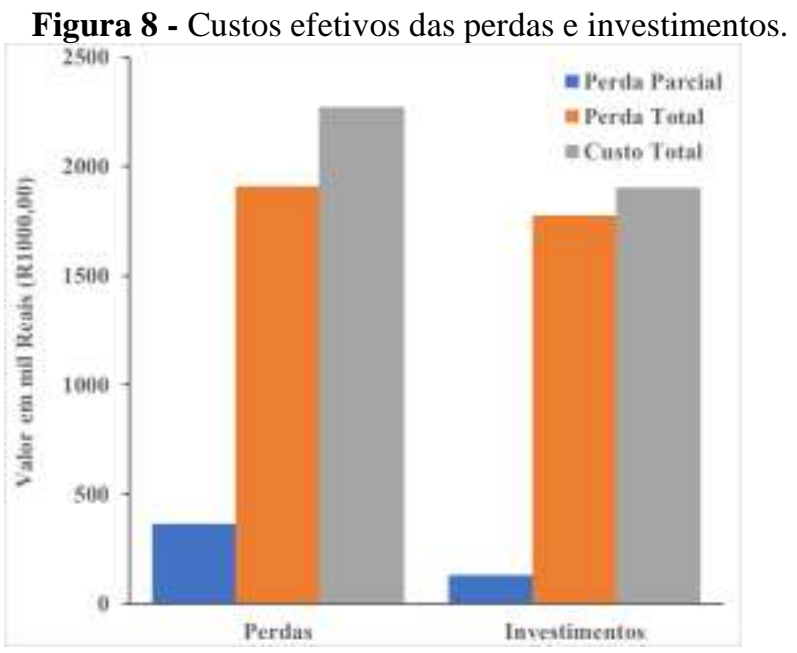

Fonte: Autores.

O Custo Efetivo estimado das perdas geradas pela erosão marinha em Ajuruteua conduz a soma dos prejuízos gerados pelas perdas e investimentos, com R \$489.000,00 nas edificações que tiveram destruição parcial do imóvel e, R \$3.676.000,00 nas edificações com destruição total do imóvel. Totalizaram diretamente aos proprietários dos estabelecimentos pesquisados, um custo/prejuízo geral na ordem $\mathrm{R} \$ 4.165 .000,00$ vinculado a perda parcial e/ou total de seus imóveis juntamente com os investimentos em recuperação, reconstrução ou realocação (Figura 8).

\subsection{Reposição - efeito externo}

Além do Custo Efetivo apresentado, o processo de erosão marinha provocou outros efeitos, principalmente em relação na economia local. Todos os estabelecimentos comerciais sentiram impactos, como a redução do número de visitantes durante 
todo o ano e de veranistas no período da alta estação, diminuindo com isso, o número de clientes/hospede e uma acentuada queda na margem de lucro. Os dados apontam que houve uma queda no número de clientes/hospedes (média de 49\%), esta redução refletiu na queda da margem de lucro (média de 60\%) nos estabelecimentos pesquisados. Assim como foi observado a redução do número de funcionários, que variou de $100 \%$, onde teve perda total, a $20 \%$ no estabelecimento que teve menor efeito externo, por ter melhor localização e melhor público de clientes (Figura 9).

Figura 9 - Efeitos indiretos (externos), dos prejuízos causados pela erosão marinha.

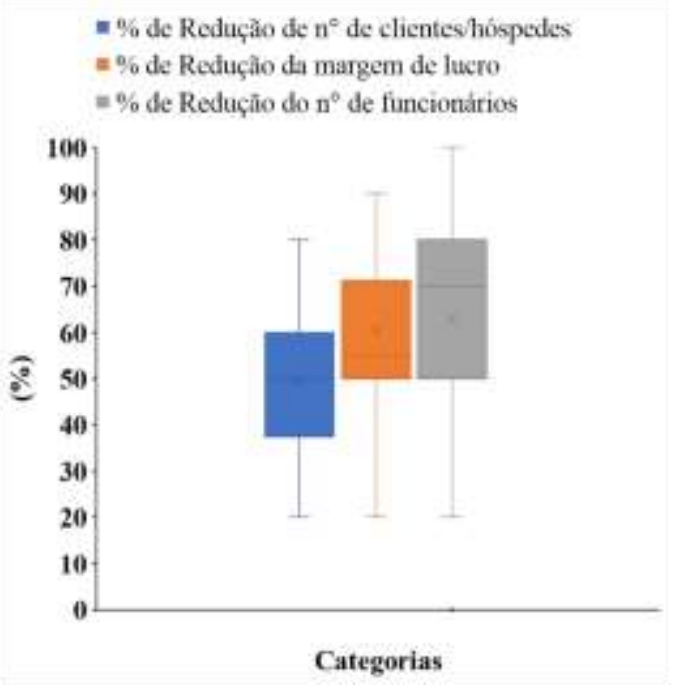

Fonte: Autores.

Durante os estudos foi identificado que uma residência foi atingida pelo fenômeno de mare alta do dia 09/02/2016, e a proprietária teve perda total de sua residência (cujo valor estimado estava na ordem de 50 mil reais); a família ficou desabrigada e sem recursos financeiros para reconstruir ou recuperar seu bem e, teve que procurar abrigo na casa de amigos e vizinhos, e até o ano de 2018 continuava dependendo de aluguel. Identificou-se também que outros bares e pousadas não tiveram prejuízos estruturais em seus estabelecimentos, mas ocorreram gastos com investimentos em estruturas de contenção (ao menos paliativas), como barreiras de concreto e/ou madeira, para evitar que a força das ondas atinja suas estruturas e os cause prejuízos.

\subsection{Cálculo do custo de reposição para recuperação da área segundo o potencial socioeconômico implantado}

Considerando o evento de erosão marinha costeira provocado pela altura de maré de 5,4 m de amplitude (que em 03 de março/2018 foi atingiu seu ponto máximo previsto pela Marinha do Brasil) foram catalogadas e identificadas 81 edificações na zona de alto risco iminente. Dentre estas, 16 são de dois pavimentos e apenas uma de três pavimentos. Estas edificações foram caracterizadas em:

1) Bar e restaurante de madeira (08 - oito edificações);

2) Bar e restaurante de alvenaria (03 - três edificações);

3) Bar pousada e restaurante de madeira (08 - oito edificações);

4) Bar, pousada e restaurante em alvenaria (03 - três edificações);

5) Residências em madeira (55 - cinquenta e cinco edificações);

6) Residências em alvenaria (02 - duas edificações) e

7) Residências mista (alvenaria e madeira, 02 - duas edificações). 
Para se realizar o cálculo do custo de reposição para recuperação da área segundo o potencial socioeconômico implantado adotou-se como Custo Unitário Interno $\left(\mathrm{CU}_{\mathrm{i}}\right)$ a média aritmética dos valos (em reais - $\mathrm{R} \$$ ) de cada edificação para a perda total do bem. E para o Custo Unitário Externo $\left(\mathrm{CU}_{\mathrm{e}}\right)$ a média aritmética dos valores (em reais - $\mathrm{R} \$$ ), estimados para a reconstrução/realocação integral do bem em outra área. Como trata-se de uma estimativa, foi considerado o mesmo "N" tanto para o $\mathrm{CU}_{\mathrm{i}}$ quanto para o $\mathrm{CU}_{\mathrm{e}}$, assim obteve-se um valor máximo considerado a perda do bem e sua possiblidade de reconstrução/realocação. Sendo que, algumas edificações em madeira podem ser desmontadas manualmente e, parte da madeira retirada pode ser reaproveitada e serem reutilizadas na realocação/reconstrução, gerando uma "economia" estimada de até $60 \%$ das perdas. Os resultados obtidos são apresentados na Tabela 2.

Tabela 2 - Avaliação de perdas segundo as categorias identificadas.

\begin{tabular}{l|c|c|c}
\hline \multicolumn{1}{c|}{ Categoria (número de edificações) } & $\begin{array}{c}\text { Descrição - Custo } \\
\text { Unitário Interno }\left(\mathrm{CU}_{\mathrm{i}}\right)\end{array}$ & $\begin{array}{c}\text { Descrição - Custo } \\
\text { Unitário Externo }\left(\mathrm{CU}_{\mathrm{e}}\right)\end{array}$ & $\begin{array}{c}\text { Valor total - Custo de } \\
\text { Reposição }(\mathrm{CR})\end{array}$ \\
\hline Bar e restaurante de madeira (8) & $\mathrm{R} \$ 13.000,00$ & $\mathrm{R} \$ 14.875,00$ & $\mathrm{R} \$ 223.000,00$ \\
\hline Bar e restaurante de alvenaria (3) & $\mathrm{R} \$ 8.333,33$ & $\mathrm{R} \$ 10.000,00$ & $\mathrm{R} \$ 54.999,99$ \\
\hline Bar, pousada e restaurante de madeira (8) & $\mathrm{R} \$ 23.125,00$ & $\mathrm{R} \$ 27.500,00$ & $\mathrm{R} \$ 405.000,00$ \\
\hline Bar, pousada e restaurante em alvenaria (3) & $\mathrm{R} \$ 161.666,66$ & $\mathrm{R} \$ 206.000,00$ & $\mathrm{R} \$ 1.102 .000,00$ \\
\hline Residências em madeira (55) & $\mathrm{R} \$ 11.836,36$ & $\mathrm{R} \$ 13.845,45$ & $\mathrm{R} \$ 1.412 .499,55$ \\
\hline Residências em alvenaria (2) & $\mathrm{R} \$ 6.500,00$ & $\mathrm{R} \$ 7.000,00$ & $\mathrm{R} \$ 27.000,00$ \\
\hline Residência mista - alvenaria e madeira (2) & $\mathrm{R} \$ 18.500,00$ & $\mathrm{R} \$ 24.500,00$ & $\mathrm{R} \$ 86.000,00$ \\
\hline
\end{tabular}

Fonte: Rodrigues (2018).

Para o Custo geral de Reposição (CR) das 81 edificações localizadas na faixa de maré, foi obtido à média aritmética de todas as edificações, tanto para o Custo Unitário Interno $\left(\mathrm{CU}_{\mathrm{i}}\right)$, quanto para Custo Unitário Externo $\left(\mathrm{CU}_{\mathrm{e}}\right)$ : $\mathrm{CU}_{\mathrm{i}}=\mathrm{R} \$ 34.708,76$, com a perda total do bem e; $\mathrm{CU}_{\mathrm{e}}=\mathrm{R} \$ 43.388,63$, com as perdas pelo custo de reconstrução/realocação integral do bem. Ambos somados ( $\mathrm{N}=81)$ geram um Custo de Reposição $(\mathrm{CR})$ na ordem de $\mathrm{R} \$ 6.325 .889,40$.

Os valores obtidos representam um retrato da situação identificada, porém estes podem variar de acordo com os critérios de gestão costeira aplicados e controle social. As estimativas de custo devem ser integradas com procedimentos de planejamento e de suporte à decisão, como análise de custo-benefício ou análise multicritério, assim como, deve-se buscar a qualidade e quantidade dos dados disponíveis (Markantonis et al., 2012). Os atores sociais tendem a incluir o caráter econômico no valor percebido, além de valores menos tangíveis, como o valor afetivo ou o relacionado com aspectos de seu bem-estar social; porém, os ecossistemas e serviços ambientais correspondentes podem ser valorados por meio da importância relativa que apresentam para as principais atividades econômicas na região considerada (Asmus et al., 2018).

Fonseca e Drummond (2003) já consideram que para discutir a valoração de ambientes costeiros é necessário avaliar que, especialmente quanto aos bens ambientais, estes têm em geral têm muitos "proprietários" ou "consumidores", que podem consumi-los sem diminuir o seu valor para outros usuários. Estes sugerem ações que se adequam a situação observada em Ajuruteua: a criação de Instrumentos Econômico-Ecológicos, que podem ser expressos por taxas ambientais municipais, ou mesmo por descontos a um "IPTU ecológico"; a criação de fóruns comunitários para negociações ambientais; e o incentivo a mutirões ecológicos comunitários, buscando desenvolver o voluntarismo ecológico aliado ao lazer.

Souza (2009) aborda o potencial do gerenciamento costeiro no Brasil para a redução dos custos associados ao controle da erosão costeira. Medeiros e Araújo (2010) avaliaram a disposição a pagar dos usuários pelo Método de Valoração de Contingente (MVC), chegando ao valor de R\$ 1.561.131,00/ano para controle da erosão na Praia do Icaraí (CE), sendo que o custo de reposição calculado para Ajuruteua foi certa de 5 vezes maior, demonstrando assim a importância do processo de gestão tanto para o dano ambiental quanto para a minimização do impacto econômico. 
Leite et al. (2019) analisaram sobre a perspectiva de disposição a pagar (DAP) por melhorias na praia da Barra do Ceará e identificaram que cerca de 54\% dos envolvidos na pesquisa estavam dispostos a fazê-lo. Costa et al. (2015) também avaliaram a disposição a pagar com base em 10 trabalhos relativos à manutenção e conservação de áreas verdes e associadas a mananciais hídricos, identificando um percentual superior a $46 \%$ de respostas de não contribuição com valor algum para a DAP. Já Ferreira et al. (2015) obtiveram na simulação da valoração ambiental (disposição a pagar pelos serviços ecossistêmicos) das praias de Ponta Negra e da Via Costeira, município de Natal (RN), o valor de cerca de 2 mil reais por hectare/ano (valor base, mínimo). Estes dados ilustram que a percepção do custo associado ao patrimônio natural e prevenção de riscos pode variar bastante de região para região e de acordo com o benefício percebido pela sociedade.

Com base nos resultados obtidos indica-se como medidas necessárias de forma imediata para Ajuruteua:

- Em caso de situação de emergência ou de estado de calamidade pública poderão ser declarados por meio de um Decreto do Prefeito Municipal em caso de novos desastres ambientais.

- Diante do contraste entre o fenômeno de erosão marinha e a ocupação desordenada da área de risco, faz-se necessário adotar medidas para evitar a exposição ao perigo instalado na praia de Ajuruteua e o enfrentamento de desastres, evitando que se tenham prejuízos ou altos custos com a recuperação, reconstrução ou realocação de imóveis e famílias que estão residentes na região e, para que outras famílias não sofram prejuízos nem sejam desalojadas. Dentre inúmeras medidas que poderão ser adotadas estão:

a) O remanejamento urgente das famílias e edificações localizadas na área de risco.

b) A proibição e fiscalização para a não ocupação da área.

c) O monitoramento e atualização da área de risco através da defesa civil do município.

- Além destas deve-se buscar de forma continuada:

a) Procedimentos de alerta da população e a promoção de eventuais reuniões de emergência, para informar sobre as providencias a serem tomadas nos casos de marés elevadas e intensas.

b) O fomento de campanhas educativas para evitar ocupações e desastres em áreas de riscos.

c) A fiscalização para a não execução de obras de contenção de efetividade duvidosa.

d) O desenvolvimento de estudos mais detalhados sobre o tipo de obra e suas relações com o ambiente de Ajuruteua.

e) E a implantação de medidas de redução da exposição ao perigo de pessoas ou famílias na orla durante os eventos de mare alta (equinócio e sizígia).

Dentre as medidas mitigadoras a mais efetiva é a prevenção através do controle e da não aceitação de instalação de novos moradores ou comerciantes em Ajuruteua-PA. Ressaltando que a praia é um patrimônio natural importante tanto para o município de Bragança quanto para o estado do Pará, advindo a necessidade de medidas que fomentem o gerenciamento costeiro associado ao gerenciamento de riscos, para que ocorra o benefício socioeconômico da região vinculado as atividades turísticas, garantida a preservação ambiental com a redução do aspecto de degradação ou a implantação de obras de contenção inadequadas e manutenção da extensão e características naturais da orla.

Para os municípios costeiros, atuar com investimentos em defesa da linha de costa envolve feedbacks que afetam desde o estoque de capital natural (por exemplo, o potencial pesqueiro local) até os modelos econômicos locais, tais como o aproveitamento turístico. Estes elementos, encontram no controle das taxas de erosão uma meta a ser alcançada para estabilidade do ambiente (Anthony et al., 2019). A gestão de riscos nestes espaços vincula-se a eventos perigosos de impactos diretos ou 
indiretos que afetam não apenas a linha costeira, mas também têm efeitos adversos, afetando a infraestrutura, deteriorando as instalações costeiras (turísticas) e os meios de subsistência (Guerrera et al., 2021). A avaliação realizada demostra que para manter a boa governança e o desenvolvimento socioambiental da região o estado deve exercer ações de proteção do litoral, compreendendo as demandas locais e buscando a redução de conflitos (Cantasano et al., 2017). Este processo pode ser bemsucedido se os tomadores de decisão entenderem que a gestão dos espaços costeiros deve ser compatível com a preservação de áreas de maior sensibilidade e restrição de ocupação, para que os benefícios possam ser longo prazo tanto no plano social quanto no nível econômico.

\section{Conclusão}

O processo erosivo em Ajuruteua é uma constante, que se manifesta com maior intensidade em determinados períodos do ano, este contrapõe-se a ocupação desordenada na área de orla da praia, que se ampliou após a conclusão da estrada que liga a praia de Ajuruteua até a sede do município de Braganca, manifestando um perigo eminente para uma tragédia anunciada devido à exposição (risco) da população, que tem este lugar como moradia ou local de trabalho.

Os resultados obtidos indicam que muitas são as tentativas para conter a erosão na linha de costa da praia de Ajuruteua, porém estas não passam de medidas paliativas de curto até médio prazo e que em muitos casos são onerosas e que não trazem soluções definitivas para o problema. Por se tratar de uma área impropria para ocupação, devido aos inúmeros eventos de maré alta, que ocasionam prejuízos/destruição dos imóveis que fazem frente a ações das ondas que solapam a costa provocando danos materiais (com prejuízo econômico superior a 4 milhões de reais em custo efetivo, obtido através do MVCR) e sociais (pessoas desalojadas/desabrigadas). Os atingidos que por não ter para onde ir recuam suas casas ou reconstroem em áreas mais abrigada da ação das ondas (efeito interno).

Não obstante também a absorção de outros efeitos econômicos para a comunidade. Estes referem-se à geração de emprego e renda para a população, conforme apontam os indicadores de redução na margem de lucro, advindo da redução do número de clientes/hospedes/visitantes afetando o setor terciário da economia local. Diante deste cenário devem ser adotadas medidas emergências para que as 81 edificações que se encontram na área de alto risco iminente, não sofram prejuízos catastróficos estimados, através do cálculo do Custo de Reposição, em mais de 6 milhos pela análise da perda e investimento na recupera do dano, no caso das edificações serem atingidas por eventos futuros.

\section{Agradecimentos}

Ao Conselho Nacional de Desenvolvimento Científico e Tecnológico (CNPq) pelo financiamento dado para o desenvolvimento da pesquisa.

\section{Referências}

Anfuso, G., Postacchini, M.; Di Luccio, D. \& Benassai, G. (2021). Coastal Sensitivity/Vulnerability Characterization and Adaptation Strategies: A Review. J. Mar. Sci. Eng., 9(72), 1-29.

Anthony, E. J., Almar, R., Besset, M., Reyns, J., Laibi, R., Ranasinghe, R., Abessolo Ondoa, G. \& Vacchi, M. (2019). Response of the Bight of Benin (Gulf of Guinea, West Africa) coastline to anthropogenic and natural forcing, Part 2: Sources and patterns of sediment supply, sediment cells, and recent shoreline variations. Cont. Shelf Res., 173, 93-103.

Armenio, E., Ben Meftah, M., De Padova, D., De Serio, F. \& Mossa, M. (2019). Monitoring systems and numerical models to study coastal sites. Sensors, 19, 1552 .

Asmus, M. L., Nicolodi, J., Scherer, E. M. G., Gianuca, K., Costa, J. C., Goersch, L., Hallal, G., Victor, K. D., Ferreira, W. L. S., Ribeiro, J. N. A., Pereira, C. R., Barreto, B. T., Torma, L. F., Souza, B. B. G., Mascarello \& M., Villwock, A. (2018). Simples para ser útil: base ecossistêmica para o gerenciamento costeiro. Desenvolvimento e Meio Ambiente, 44. 
Barbosa, V. M., Gregório, A. M. S., Costa, R. A. A. M., Braga, P. W. \& Pereira, L. C. C. (2007). Estudo morfodinâmico durante uma maré equinocial de sizígia em uma praia de Macromaré do litoral amazônico (Praia de Ajuruteua-PA, Brasil). Boletim Paranaense de Geociências, 60-61, 31-43.

Braga, F. P. S., Souza Filho, P. W., Alves, M. A. M. S. \& Pereira, L. C. (2007). Morfologia e sedimentologia da praia de macromaré de Ajuruteua, Amazônia, Norte do Brasil. Boletim Paranaense de Geociências, 60-61, 11-30.

Bruno, M. F., Molfetta, M. G., Pratola, L., Mossa, M., Nutricato, R., Morea, A., Nitti, D. O. \& Chiaradia, M. T. (2019). A combined approach of field data and earth observation for coastal risk assessment. Sensors, 19, 1399.

Calliari, L. J., Muehc, D., Hoefel, F. G. \& Toldo Jr., E. (2003). Morfodinâmica praial: uma breve revisão. Revista Brasileira de Oceanografia, $51,63-78$.

Cantasano, N., Pellicone, G. \& Ietto, F. (2017). Integrated coastal zone management in Italy: A gap between science and policy. J. Coast. Conserv., 21, 317325 .

Corrêa, R. S. \& Souza, A. N. (2013). Valoração de danos indiretos em perícias ambientais. Revista Brasileira de Criminalística, $2(1)$, 7-15.

Costa, M. E. L., Souza, R. A. T. M., Ribeiro, A. R. \& Pasa, M. C. (2015). Respostas de protesto na disposição a pagar espontânea e induzida nas técnicas de lances livres e referendo pelo método de valoração contingente. Biodiversidade, 14(1), 117-144.

Costa, N. B. R. (2011). Impactos socioambientais do turismo em áreas litorâneas: um estudo de percepção ambiental nos balneários de praia de leste, Santa Teresinha e Ipanema - Paraná. Revista Geografar, 6(2), 151-181.

CPRM. (2015). Reconhecimento de áreas de alto e muito alto risco a movimentos de massa e enchentes: Bragança, Pará. Produto Cartográfico, Belém: CPRM - Serviço Geológico do Brasil.

De Serio, F. \& Mossa, M. (2016). Environmental monitoring in the Mar Grande basin (Ionian Sea, Southern Italy). J. Environ. Sci. Pollut. Res., 23, 1266212674.

Díaz-Cuevas, P., Prieto-Campos, A. \& Ojeda-Zújar, J. (2020). Developing a beach erosion sensitivity indicator using relational spatial databases and Analytic Hierarchy Process. Ocean Coast. Manag., 189, 105-146.

El-Robrini, M., Silva, M. M. A., Souza Filho, P. W. M., El-Robrini, M. H., Silva Júnior, O. G. \& França, C. F. Pará. (2006). In: Muehe, D. Erosão e progradação no litoral brasileiro. Brasília: MMA, 41-86.

Enríquez, A. R., Marcos, M., Álvarez-Ellacuría, A., Orfila, A. \& Gomis, D. (2017). Changes in beach shoreline due to sea level rise and waves under climate changes cenarios: application to the Balearic Islands (western Mediterranean). Natural Hazards Earth System Sciences, 17, $1075-1089$.

Eric, L. G. \& Rémi, M. A. (2015). systematic review of socio-economic assessments in support of coastal zone management (1992-2011). Journal of Environmental Management, 149, 85-96.

Espirito-Santo, C. M. \& Szlafsztein, C. F. (2016). Disaster risk management in urban master plans in three municipalities of the coastal area of Pará State, Brazil. Journal of Integrated Coastal Zone Management, 16(2), 223-229.

Ferreira, J. C. V, Silva, E. E. S, Amaro, V. E, Esteves, L. S. \& Fernandes, E. (2015). Serviços ambientais oferecidos pelas praias de Ponta Negra e via costeira: perspectivas de valoração. Revista do CERES, 1(2), 1-7.

Fonseca, S. M. \& Drummond, J. A. (2003). O valor de existência de um ecossistema costeiro tropical através da disposição ao trabalho voluntário: o caso da lagoa de Itaipu (Niterói, RJ). Ambiente \& Sociedade, 5(2), 85-107.

França, M. V., Medeiros, R. M., Araújo, W. R. \& Holanda, R. M. (2020). Variabilidade dos índices de aridez e aplicabilidade da equação de perda de solo no município de Amparo de São Francisco - Sergipe, Brasil. Research, Society and Development, 9(10), p. e5609108756.

Gomes, R., Pereira, L., Ribeiro, C. \& Costa, R. (2009). Dinâmica socioambiental em uma comunidade pesqueira amazônica, PA, Brasil. Revista de Gestão Costeira Integrada, 9(2), 101-111.

Guerrera, F., Martín-Martín, M., Tramontan, M., Nimon, B. \& Essotina Kpémoua, K. (2021). Shoreline Changes and Coastal Erosion: The Case Study of the Coast of Togo (Bight of Benin, West Africa Margin). Geosciences, 11(40), 1-21.

Igwe, O. \& Fukuoka, H. (2010). Environmental and socio-economic impact of erosion in Nigeria, West Africa. International Journal of Erosion Control Engineering, 3(1), 103-109.

Leite, J. S., Moraes, C. R. F., Medeiros, D. H. M. \& Salazar, I. S. O. (2019). avaliação da disposição a pagar dos frequentadores de uma praia pelos benefícios ambientais. GeoTemas, 9(1), 70-86.

Markantonis, V., Meyer, V. \& Schwarze, R. (2012). Valuating the intangible effects of natural hazards - review and analysis of the costing methods. Natural Hazards Earth System Sciences, 12, 1633-1640.

Medeiros, E. C. \& Araújo, R. C. P. (2009). Valoração econômica dos serviços ambientais do controle de erosão da praia do Icaraí, Caucaia-CE. In: SOBER, 48, Campo Grande - MS. Anais ... Campo Grande - MS: Sociedade Brasileira de Economia, Administração e Sociologia Rural, 1-18.

Mendes, R. M. L., Kawamoto, M. S., Barreiros, M. N., Moraes, S. M. \& Mourão, F. V. (2013). Análise dos impactos ambientais ocasionados por resíduos sólidos pelo fluxo turístico na ilha de Ajuruteua-PA. In: Congresso Nacional de Meio Ambiente, 10, Poços de Caldas - MG. Anais ... Poços de Caldas - MG: IFMG, 1-5.

Mohamad, M. F., Lee, L. H. \& Samion, M. K. H. (2014). Coastal Vulnerability Assessment towards Sustainable Management of Peninsular Malaysia Coastline. International Journal of Environment Science and Development, 5(6), 533-538. 
Monteiro, M. C., Pereira, L. C. C., Guimarães, D. O. \& Costa, R. M. (2009). Ocupação territorial e variações morfológicas em uma praia de macromaré do litoral Amazônico, Ajuruteua-PA, Brasil. Revista de Gestão Costeira Integrada, 9(2), 91-99.

Mullick, M. R. A., Tanim, A. \& Islam, S. M. S. (2019). Coastal vulnerability analysis of Bangladesh coast using fuzzy logic based geospatial techniques. Ocean Coast. Manag., 174, 154-169.

Oliveira, S. M. O., Pereira, L. C. C., Vila-Concejo, A., Gorayeb, A., Sousa, R. C., Souza Filho, P. W. M. \& Costa, R. M. (2011). Natural and anthropogenic impacts on a macrotidal sandy beach of the Brazilian Amazon (Ajuruteua, Para): guidelines for coastal management. Journal of Coastal Research, 64, 13851389.

Pereira, L. C. C., Ribeiro, M. J. S., Guimarães, D. O., Souza Filho, P. W. \& Costa, R. M. (2006). Formas de uso e ocupação na praia de Ajuruteua-Pará (Brasil). Desenvolvimento e Meio Ambiente, 13, 19-30.

Pereira, L. C., Tôsto, S. G. \& Carvalho, J. P. (2015). Erosão do solo e valoração de serviços ambientais. Serviços Ambientais em Sistemas Agrícolas e Florestais do Bioma Mata Atlântica. Brasília: Empresa Brasileira de Pesquisa Agropecuária - Embrapa, 317-323.

Prasad, D. H. \& Kumar, N. D. (2014). Coastal Erosion Studies - A Review. International Journal of Geosciences, 5 , $341-345$.

Ranieri, L. \& El-Robrini, M. (2013). Evolução da linha de costa de Salinópolis, Nordeste do Pará, Brasil. Pesquisas em Geociências, 42,3 , $207-226$.

Ribeiro, J. S., Sousa, P. H. G. O., Vieira, D. R. \& Siegle, E. (2013). Evolução da vulnerabilidade à erosão costeira na Praia de Massaguaçú (SP), Brasil. Revista de Gestão Costeira Integrada, 13(3), 253-265.

Ribeiro, W. O. (2018). Cidade de porte médio de importância histórica: particularidades de Bragança no Nordeste do Pará. Caderno de Geografia, 28(52), 1-24.

Rodrigues, H. S. (2018). Análise de perdas econômicas geradas pela erosão em ambiente praiano: caso da praia de Ajuruteua - Bragança/PA (Dissertação de mestrado). Instituto de Geociências, Universidade Federal do Pará, Belém, PA, Brasil.

Santos, M. S. T., Amaro, V. E., Ferreira, A. T. S., Barboza, A. A., Figueiredo, M. C. \& Araújo, A. G. (2015). Metodologia para mapeamento de vulnerabilidade costeira a elevação do nível médio do mar (NMM) em escala local. Boletim de Ciências Geodésicas, 21(4), 691-705.

Souza Filho, P. W. M., Tozzi, H. A. M. \& El Robrini, M. (2003). Geomorphology, land use and environmental hazards in Ajuruteua macrotidal sand beach, Northern Brazil. Journal of Coastal Research, 35, 580-589.

Souza, C. R. G. (2009). A Erosão Costeira e os Desafios da Gestão Costeira no Brasil. Revista de Gestão Costeira Integrada, 9(1), $17-37$.

Suryanto, S., Gravitiani, E. \& Susilowati, F. (2017). Vulnerability and willingness to pay for coping with flood in Klaten Regency, Central Java, Indonesia. Journal of Business and Economics Review, 2(2), 38-44.

Tôsto, S. G., Pereira, L. C., Romeiro, A. R., Paiva Sobrinho, R., Andrade, D. C. \& Valladares, G. S. (2007). Valoração da erosão do solo e a sustentabilidade ambiental no espaço rural do município de Araras, SP. Brasília: Empresa Brasileira de Pesquisa Agropecuária - Embrapa, $309-321$.

Van Assche, K., Hornidge, A. K., Schlüter, A. \& Vaidianu, N. (2019). Governance and the coastal condition: Towards new modes of observation, adaptation and integration. Mar. Policy, 112, 1-10.

Vaz, E. \& Bowman, L. (2013). An application for regional coastal erosion processes in urban areas: a case study of the Golden Horseshoe in Canada. Land, 2, 595-608.

Vergara, F. E. V., Sousa, R. A. M. \& Andrade, R. S. (2014). Aplicação do método do custo de reposição (MCR) para valoração do meio ambiente: o caso do Parque Cesamar, Palmas - TO. Revista Monografias Ambientais, 13(5), 4063-4076.

Victral, D. M., Grossi, L. B., Ramos, A. M. \& Gontijo, H. M. (2020). Sustentabilidade econômica das políticas públicas de abastecimento de água nas regiões semiáridas do Brasil. Research, Society and Development, 9(6), p. e65963435.

Zucatelli, P. J., Meneguelo, A. P., Diniz Chaves, G. L., Chaves, G. L. D. \& Tosta, M. C. R. (2019). Aplicação, investimentos necessários e custos operacionais do sequestro geológico de $\mathrm{CO}_{2}$ : um estudo de caso. Research, Society and Development, 8(6), p. e12861023. 